\title{
Gestão ambiental aplicada a postos de abastecimento de combustíveis
}

Diogens Marco de Brito da Cruz diogens_brito@hotmail.com.br

Faculdade Santíssimo Sacramento (FSSS), Alagoinhas, BA, Brasil

\section{Lucas Magno Neris} magno17@hotmail.com Faculdade Santíssimo
(FSSS), Alagoinhas, BA, Brasil

Jeane Denise de Souza Menezes gestãoambientalfsss@gmail.com Faculdade Santíssimo Sacramento (FSSS), Alagoinhas, BA, Brasil

\begin{abstract}
RESUMO
O comércio varejista de postos de combustíveis apresenta parcela significativa na estatística de empresas poluidoras do meio ambiente. Por conta desse aspecto, esse segmento tem buscado atender a duas vertentes: o manuseio de produtos derivados do petróleo e a interação harmoniosa com o meio ambiente. Nesse contexto, surgiu a necessidade de se analisar e identificar a interação dessas entidades com o meio ambiente e mostrar quais medidas mitigadoras são adotadas para minimizar os impactos ambientais. Para tanto, este trabalho consiste em estudo de caso em um posto de combustível em uma cidade do litoral norte da Bahia com objetivo de verificar e analisar as principais medidas de gestão ambiental adotadas por esse estabelecimento, tendo como referência a legislação vigente. Foram utilizados para o estudo de caso dados qualitativos aliados a uma entrevista estruturada, utilizando também a técnica de observação para uma melhor análise do tema. Os resultados apontaram que o estabelecimento em estudo realiza tratamento de alguns resíduos e efluentes gerados pelas atividades exercidas, no entanto carece de seguir itens importantes preconizados pela legislação. Contudo, ficou constatado que o estabelecimento está em fase inicial de implantação da gestão ambiental buscando atender integralmente a legislação vigente.
\end{abstract}

PALAVRAS-CHAVE: Legislação Ambiental. Gestão Ambiental. Postos de Combustíveis. 


\section{INTRODUÇÃO}

A humanidade despertou para as questões ambientais recentemente, nesse contexto houve a necessidade de adotar uma proteção ambiental mais rígida. Entretanto, o meio ambiente já se deparava com fortes impactos ambientais causados na natureza, esses efeitos foram sentidos principalmente na última década com o aquecimento global e o aumento do efeito estufa. Segundo Barata et al. (2007), as empresas com um alto potencial poluidor buscam desenvolver e implantar medidas de gestão ambiental no estabelecimento para obter um melhor fluxo interno e externo das informações para que assim evitem penalidades por parte dos órgãos ambientais de fiscalização.

No que tange a periculosidade dos postos de combustíveis, o ramo de revenda de derivados do petróleo é considerado potencialmente poluidor para o meio ambiente, sendo que esta atividade deve adequar-se às normas e procedimentos, para evitar assim, a poluição de águas subterrâneas, rios, florestas, bem como a alteração da qualidade do ar na região (LORENZETT; ROSSATO, 2010). Segundo a Federação Nacional do Comércio de Combustíveis e Lubrificantes FECOMBUSTÍVEIS (2011) a preocupação ambiental tornou-se um pensamento comumente adotado pelos empresários do ramo de revenda de combustíveis, sendo necessário aos mesmos, o cumprimento de inúmeras normas e procedimentos cabíveis às legislações estaduais específicas.

O comércio varejista de combustíveis é regido por resoluções que visam proteger o meio ambiente como é o caso da resolução do Conselho Nacional do Meio Ambiente CONAMA 273/2000 que dispõe sobre prevenção e controle da poluição em postos de revenda de combustíveis e de serviços. Nesse âmbito, os empreendedores que realizam atividades de varejo de combustíveis necessitam aderir às normas dos órgãos que regulamentam esse ramo, como é o caso da Agência Nacional do Petróleo, Gás Natural e Biocombustíveis (ANP) que exerce a função de regular as atividades da indústria de petróleo, bem como o comércio dos combustíveis derivados do petróleo. Devendo seguir, também, as normas da Associação Brasileira de Normas Técnicas (ABNT) e a legislação estadual específica de cada estado.

Esse estudo justifica-se pela necessidade de difusão do conhecimento das práticas ambientais aplicadas aos postos de combustíveis. Nesse contexto, o trabalho evidenciou a necessidade de um posto adequar-se às normas e legislações vigentes. Analisou, também, alguns aspectos da gestão ambiental adotadas pelo posto de combustível de uma cidade do Litoral Norte da Bahia.

\section{REFERENCIAL TEÓRICO}

\section{POSTOS DE COMBUSTIVEIS}

Os postos de revenda de combustíveis estão entre os maiores poluidores ambientais da década atual, por esse motivo eles precisam ser regidos por leis e normas ambientais, como é o caso da Resolução CONAMA no 273/2000 que dispõe sobre o controle da poluição e prevenção dos impactos ambientais causados pelo comércio varejista de combustível, bem como o licenciamento ambiental para tal atividade. Este ramo de atividade possui altos índices de acidentes por trabalhar 
com combustíveis poluidores e inflamáveis que ficam armazenados em tanques no subsolo do posto (KERBER, 2013).

Para a prevenção de acidentes ambientais os postos de combustíveis geralmente possuem tanques de armazenamento de combustíveis, que se interligam com as bombas abastecedoras de combustíveis por meio de linhas (tubulações) produzidos de polyviny chloride, conhecido como PAD, sendo uma parte dessa linha flexível. Em volta da área de abastecimento de veículos se encontram calhas do sistema de drenagem que por sua vez levam, para caixa separadora de água e óleo, todo derramamento de substância existente na área das bombas abastecedoras. Na pista de abastecimentos também são encontrados os filtros de diesel. Em alguns casos, os estabelecimentos possuem centros de lubrificação e lavagem, também são encontrados em toda a parte externa do posto equipamentos de proteção à incêndio (CONAMA, 2016).

O comércio varejista de combustível realiza várias atividades em suas intermediações como transportar, armazenar e revender produtos que podem causar danos ao meio ambiente (LORENZETT; ROSSATO, 2010). Em caráter ambiental uma das preocupações é a contaminação do solo e das águas subterrâneas, pois em casos extremos até mesmo os lençóis freáticos podem ser contaminados, causando danos incalculáveis ao meio ambiente. Os incêndios causados devido a falhas de operação têm afetado de maneira direta a natureza, assim como os resíduos gerados pelo empreendimento, classificados pela Norma Brasileira Regulamentadora NBR 10004/1987 como classe I que são os resíduos perigosos, portanto merecem cuidados especiais, pois são os principais responsáveis pelos danos ambientais da atividade de revenda de combustíveis.

\section{LEGISLAÇÃO E FISCALIZAÇÃO AMBIENTAL APLICÁVEL AOS POSTOS DE COMBUSTÍVEIS}

A Lei Federal no 6938 de 31 de agosto de 1981 que dispõe sobre a política de meio ambiente, regulamentada pelo Decreto Federal no 99.274/90, instituiu o Conselho Nacional de Meio Ambiente - CONAMA. Esse órgão classifica o ramo de comércio e varejo de combustível como uma atividade parcialmente ou altamente poluidora e utilizadoras de recursos ambientais (CONAMA, 1981).

A Resolução CONAMA no 237 de 1997 regulamentada e padronizada pela Resolução 273 de 2000 sujeitou aos postos de combustíveis ao licenciamento ambiental. A licença ambiental é usada pelo órgão de controle ambiental para permitir a instalação de projetos e atividades com alto potencial de impactos ambientais. De acordo o Art. 4을 dessa resolução será exigida dos postos de combustíveis as seguintes licenças para poder operar:

I - Licença Prévia-LP: concedida na fase preliminar do planejamento do empreendimento aprovando sua localização e concepção, atestando a viabilidade ambiental e estabelecendo os requisitos básicos e condicionantes a serem atendidos nas próximas fases de sua implementação;

II - Licença de Instalação-LI: autoriza a instalação do empreendimento com as especificações constantes dos planos, programas e projetos aprovados, incluindo medidas de 
controle ambiental e demais condicionantes da qual constituem motivo determinante;

III - Licença de Operação-LO: autoriza a operação da atividade, após a verificação do efetivo cumprimento do que consta das licenças anteriores, com as medidas de controle ambiental e condicionantes determinados para a operação.

$\S 1$ 을 licenças Prévia e de Instalação poderão ser expedidas concomitantemente, a critério do órgão ambiental competente.

§ 2ㅇ Os estabelecimentos definidos no art. 2ㅇ que estiverem em operação na data de publicação desta Resolução, ficam também obrigados à obtenção da licença de operação. (CONAMA, 2000).

Segundo o Art. 8o da referida resolução em caso de apresentar alguma situação de perigo ao meio ambiente e às pessoas, o responsável legal responderá solidariamente pelas medidas de combate da situação. O Art. 10 으 se refere à certificação de equipamentos e o Art. $12 \circ$ é tratada da sanção e pena em caso de descumprimento das leis ambientais impostas ao ramo (CONAMA, 2000).

Aos municípios do Estado da Bahia compete proceder à liberação do licenciamento ambiental, cabendo ao empreendedor optar pelo licenciamento municipal ou estadual. Os municípios contam com apoio de equipe especializada e do órgão de regulamentação ambiental no Estado da Bahia: Instituto do Meio Ambiente e Recursos Hídricos - INEMA. A Lei Estadual no 10.431 de 2006, alterada pela Lei 12.377 de 8 de dezembro 2011, reestrutura o Grupo Ocupacional Fiscalização e Regulamentação, trazendo uma nova modalidade de licenciamento: a Licença de Regulamentação - LR. Concedida para regulamentação de empreendimentos de pequeno e médio porte que se encontram em recuperação ambiental de áreas degradadas, mediante a Licença Ambiental por Adesão e Compromisso - LAC que é concedida eletronicamente (INEMA, 2011).

É imprescindível aos estabelecimentos atender os requisitos estabelecidos na NBR 13784 da ABNT, que normatizam detecção de vazamento, na NBR 12235 da $A B N T$, que normatizam o armazenamento dos resíduos gerados pela atividade e NBR 10004 da ABNT, que dispõe sobre embalagens de produtos considerados perigosos (ABNT, 2017).

A Lei no 9.605 de 1998, alterada pela Lei 12.305 foi instituída a Política Nacional de Resíduos Sólidos - PNRS em agosto de 2010, atribuindo ao Instituto Brasileiro do Meio Ambiente e dos Recursos Naturais Renováveis (IBAMA) o dever de gerir projetos para embater o avanço de atividades e obras com significativo impacto ambiental, também de controlar e fiscalizar ações voltadas aos resíduos sólidos (IBAMA, 2017). Segundo a Resolução CONAMA no 362 de 2005, alterada pela Resolução no 450, de 2012 que dispõe sobre o recolhimento, bem como a coleta e destinação do óleo lubrificante usado ou contaminado, cita que:

Art. 1o Todo óleo lubrificante usado ou contaminado deverá ser recolhido, coletado e ter destinação final, de modo que não afete negativamente o meio ambiente e propicie a máxima 
recuperação dos constituintes nele contidos, na forma prevista desta resolução (CONAMA, 2005).

Devido à vasta legislação ambiental, a qual se altera com bastante frequência, é importante que o empreendedor mantenha situação de regularidade, devido às penalidades constantes o Decreto Federal no 6.514 de 22 de julho de 2008, e no Decreto Estadual no 44.844 cujas atuações divergem de interdição do posto a multas que variam de $\mathrm{R} \$ 50$ a $\mathrm{R} \$ 50$ milhões (BRASIL, 2008).

\section{GESTÃO AMBIENTAL EM POSTOS DE DISTRIBUIÇÃO DE COMBUSTÍVEIS}

A gestão ambiental tem como princípio coordenar as atividades humanas, a fim de que, estas minimizem os possíveis impactos ambientais, orientando desde a escolha das melhores técnicas até o cumprimento da legislação para o destino correto de recursos financeiros e humanos (COSTA et al. 2013). Neste sentido, a gestão ambiental representa um grande desafio, onde a organização precisa buscar alinhar suas atividades com a preservação ambiental (FREY; WITTMANN, 2006).

O gerenciamento ambiental em postos de combustíveis, pode ser entendido, segundo Lorenzett, Rossato e Neuhaus (2011), como procedimentos e ações adotados pelo estabelecimento que contribuem para a diminuição dos impactos de suas atividades, que vão desde a implantação de instalações mais seguras até a manutenção de áreas de preservação ambiental.

É de extrema importância que os revendedores de combustíveis planejem de forma eficaz e eficiente a utilização da gestão ambiental em suas atividades, para que não venham a degradar o meio ambiente. Segundo Lorenzett et al. (2011), a gestão ambiental busca alinhar as atividades desenvolvidas pelo estabelecimento com o desenvolvimento sustentável, assim proporcionando uma redução dos impactos causados no meio ambiente. A partir da International Organization for Standardization ISO 14001:2015 que dispõe sobre requisitos para elaboração e implementação de sistemas de gestão ambiental em uma organização, as empresas independentemente do tamanho passaram a desenvolver práticas ambientalmente sustentáveis em seus negócios e produtos, evitando assim impactos ambientais.

Os principais geradores desses impactos no meio ambiente são oriundos do manejo inadequado dos resíduos sólidos e efluentes em postos de combustíveis, como o descarte de mantas, estopas, conexões danificadas, causando contaminações no solo, águas superficiais e subterrâneas. É válido ressaltar que a emissão de substâncias químicas é feita pelo respiro dos tanques enterrados, modificando a qualidade do ar, bem como incêndios e explosões que são causados pela presença de alguma fonte de ignição, podendo ser causado por pessoas ou reações químicas adversas. Ainda constatando que o derrame de produtos é causado pelo extravasamento, interagindo com o solo e impactando sobre águas superficiais, águas subterrâneas e outros recursos naturais (LORENZETT; ROSSATO, 2010).

Portanto, pode se notar que um revendedor de combustível interfere no meio ambiente de forma contínua, podendo assim contaminar águas subterrâneas, rios, florestas bem como interferir na qualidade do ar na região. Assim, deve ocorrer o 
uso adequado das normas brasileiras regulamentadoras previstas pela ABNT para tal diminuição dos impactos ambientais e preservação do meio ambiente. Segundo Leite (2003), o não cumprimento dessas normas causam impactos ambientais contínuos, assim, a legislação atua para que esses impactos sejam minimizados progressivamente no meio ambiente, e que, assim, não venham a causar danos irreversíveis na natureza.

\section{METODOLOGIA DA PESQUISA}

A metodologia abordada no presente trabalho foi um estudo de caso de uma empresa numa cidade do Litoral Norte da Bahia no período de janeiro a junho de 2017. Por meio de dados qualitativos buscou-se analisar e identificar as principais irregularidades que um posto de combustível enfrenta no que se refere a gestão ambiental e a legislação que rege esta atividade. Para uma melhor abordagem do tema houve a necessidade de uma pesquisa bibliográfica acerca do assunto proposto, onde se buscou informações em livros, sites, revistas e artigos publicados.

O presente estudo foi realizado em um posto do ramo de revenda de combustível que funciona há 43 anos no mercado, com cerca de 13 funcionários efetivos, e área correspondente a 64.543,38 m2, o mesmo realiza várias atividades em suas intermediações, sendo elas:

- Abastecimento de combustíveis: a empresa possui seis unidades de abastecimento de combustíveis, com a presença de dois frentistas para a realização do atendimento aos clientes;

- Armazenamento de combustíveis: o estabelecimento dispõe de dois tanques de combustíveis (subterrâneos) com capacidade de 30 mil litros de combustível cada, cinco tanques de 15 mil litros cada, e ainda um Ponto de Reabastecimento de Combustível - PRC.

- Lavagens de veículos: a empresa disponibiliza para os clientes um espaço para lavagem de seus veículos, bem como a limpeza geral dos automóveis e motocicletas;

- Loja de conveniência: nessa atividade é realizada a produção de lanches, café da manhã, almoços e jantares para os clientes e colaboradores, sendo que o posto utiliza a água da chuva para lavagem do piso da loja;

- Oficina mecânica: o estabelecimento possui dois mecânicos automotivos para realização das atividades de troca de óleo, filtros e de lubrificação dos veículos, bem como a manutenção preventiva, preditiva e corretiva dos veículos;

- Área de parada para veículos: o posto reserva para os motoristas de veículos com mais de $3 \mathrm{~m}$ de comprimento cerca de aproximadamente $29.643,00 \mathrm{~m} 2$ de área para parada e descansos diários.

Os dados foram obtidos com a realização de uma entrevista estruturada (Apêndice A) com os frentistas e o gerente do posto que aliada à técnica de observação nos setores de abastecimento, manutenções veiculares e loja de 
conveniência que proporcionou um melhor discorrimento do tema, bem como o levantamento das medidas de gestão ambiental que o posto adota.

\section{RESULTADOS E DISCUSSÃO}

\section{GESTÃO AMBIENTAL DO SETOR DE ABASTECIMENTO DE COMBUSTÍVEL}

Como medida de gestão ambiental no local de abastecimento, os postos devem seguir normas, como a ABNT NBR 13784, referenciando sobre possíveis detecções de vazamentos de tanques de combustíveis. Sendo que os postos distribuidores de combustíveis devem adotar outras medidas de gestão ambiental cabíveis às situações, sendo constatado que houve a troca de um tanque antigo que apresentava oxidação em sua estrutura, por outro novo fabricado recentemente, evitando assim, um possível vazamento de combustível no solo.

A figura $1 \mathrm{~A}$ expõe um tanque de combustível novo que foi inserido pela empresa após o tanque da figura $1 \mathrm{~B}$ apresentar descontinuidades em sua estrutura metálica. Conforme a ABNT NBR 7505-1 que dispõe sobre armazenamentos de líquidos inflamáveis, exigem que os tanques ao apresentar algum tipo de descontinuidade em sua estrutura necessitem de troca imediata, pois são considerados inutilizáveis para tal atividade.

Figura 1 - Tanque de combustível novo (A) e tanque desgastado substituído (B)
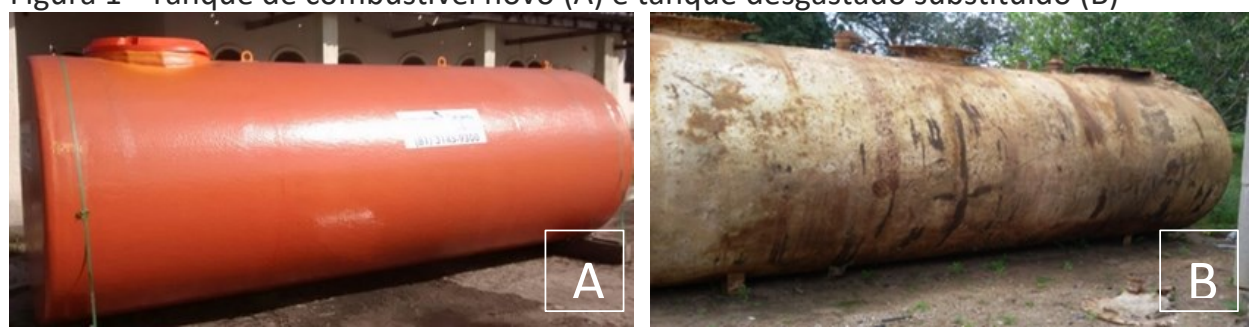

Fonte: Pesquisa de campo (2017)

Através de medidas como essa, evitou-se um possível impacto ambiental que prejudicaria o solo, ar e lençóis freáticos da região, bem como as pessoas envolvidas na atividade. Assim, como previsto na norma ISO 14001:2015 que dispõe de sistemas de gestão ambiental, o posto identificou e evitou um possível risco ambiental que causaria um grande impacto na natureza, por ter uma alta probabilidade de vazamento no solo e assim uma contaminação no lençol freático da região.

Lorenzett, Rossato e Neuhaus (2011) em um estudo realizado na cidade de Santa Maria (RS) evidenciou a necessidade do posto estudado de implementar medidas de controle ambiental na adoção de tanques ecológicos anticorrosivos para evitar possíveis vazamentos de combustível no solo, como também, a implementação de dois poços de monitoramento dos tanques subterrâneos, evitando assim, impactos irreversíveis no meio ambiente. Esta mesma empresa, estudada por Lorenzett, Rossato e Neuhaus (2011) conseguiu investir em ações que superam as legislações atuais, como é o caso do tratamento e reutilização da água proveniente da chuva.

Por meio das observações foi constatado que o posto analisado não realiza a coleta semestral das amostras dos poços de monitoramento para verificação da 
qualidade da água subterrânea e para o controle e deteç̧ão de vazamentos do sistema de abastecimento subterrâneo de combustíveis. Assim, se houvesse uma possível liberação de combustível por meio do tanque oxidado o posto não tinha como quantificar o grau do impacto ambiental causado no meio ambiente. Sousa et al. (2011) e Bezerra et al. (2012) alertam sobre a contaminação de águas subterrâneas por vazamentos em postos de combustíveis e reforçam a necessidade da instalação de poço de monitoramento com objetivo de minimizar o impacto ambiental e protegendo a população local de possíveis agressões à saúde.

No descarregamento dos líquidos inflamáveis foi observado que o posto possui um sistema de mangueiras e conexões que evita o vazamento durante a descarga do combustível. Segundo a ABNT NBR 15594-1, essa é uma operação que oferece risco de acidente e contaminação, assim, é preciso em primeira instância posicionar o caminhão tanque (CT) de forma que, em caso de emergência, ele possa sair rapidamente, em seguida certifica-se que não há fonte de explosão em um raio de 3 metros. Logo após, proceder com as normas de segurança colocando cones e placas de sinalização, extintores e cabo terra. Por fim, verificar se o motorista conectou a descarga selada na boca do tanque subterrâneo. Em seguida, conectar o engate rápido do mangote na válvula do compartimento que será descarregado. Quando descarregando garantir que o condutor do CT acompanhe a operação e não se afaste da área.

$\mathrm{Na}$ área de abastecimento, verificou-se que o posto possui canaletas que cercam todas as bombas de combustíveis, levando os efluentes para a caixa separadora de água e óleo para que ocorra a separação dos fluidos. Entretanto, foi observado no posto de combustível estudado, que o mesmo não está cumprindo com algumas normas estabelecidas pela ABNT NBR 15594-3, como a manutenção preventiva da caixa separadora de água e óleo que deve ser verificada periodicamente, sendo que a mesma pode contaminar o solo e águas subterrâneas através de vazamentos em sua estrutura.

Como são os próprios funcionários do posto que realizam a atividade de limpeza do equipamento de separação de água e óleo, foi constatado que os resíduos retirados após a limpeza são despejados no esgoto comum por não conter um local para despejo adequado do material, assim a empresa lança esses fluidos diretamente no meio ambiente para a redução de custos com o manejo adequado desses materiais através de uma empresa especializada. Essa atividade é feita regularmente sempre que a caixa separadora está em seu nível de efluentes mais elevado.

Os custos para a remoção desses resíduos e adequação as normas são elevados, devido a isso, muitos postos ainda insistem em não realizar a coleta ou tratamento dos resíduos. Um estudo realizado por Lorenzett, Rossato e Neuhaus (2011) em um posto de combustível localizado na cidade de Santa Maria/RS, mostrou um levantamento das medidas de gestão ambiental exigidas pela legislação, como requisito para exercer a atividade de posto de combustível e concluíram que os custos da adequação é a principal dificuldade no momento da tomada de decisões.

Através das observações, constatou-se que o posto estudado analisa diariamente o Livro de Movimento de Combustível (LMC) que permite ao estabelecimento detectar possíveis vazamentos em seus tanques, bombas e 
tubulações observando o fluxo do volume de combustível, pois havendo divergências no controle de entradas e saídas poderá haver possíveis vazamentos durante o processo. Através de exigências como essa, o posto busca identificar e conter possíveis impactos ambientais. Assim, o estabelecimento possui pelo menos dois funcionários treinados para a contenção de acidentes ambientais, atendendo as exigências do órgão fiscalizador municipal.

É valido ressaltar que o proprietário cumpre com alguns requisitos da legislação para obter determinadas licenças, como é o caso da licença de operação, sendo constatado que a pista de abastecimento é impermeável e com drenagem conectada a caixa separadora, ressaltando que o abastecimento dos tanques subterrâneos somente poderá ser realizado por veículo licenciado para fontes móveis de poluição no órgão ambiental.

Barboza, Teixeira e Lima (2017) ao realizarem um estudo em um posto de combustível na cidade de Itaipuaçu utilizando a técnica HazOp (em inglês Hazard and operability study) que significa em termos livres estudo de riscos e operabilidade, concluíram que um dos principais riscos à saúde humana, bem como ao meio ambiente, ocorre no momento que o caminhão tanque descarrega e abastece os tanques subterrâneos, sendo que, qualquer fonte de ignição derivada de manuseio inadequado ou até mesmo uma falha mecânica em equipamentos pode causar explosões e impactos ambientais seja no solo, águas ou ar. Assim, através da análise HazOp, os mesmos observaram que para a prevenção desses incêndios e explosões é necessário em primeira instância, realizar inspeções periódicas no equipamentos e sempre manter os funcionários bem treinados caso ocorra um incidente no descarregamento de combustível.

\section{GESTÃO AMBIENTAL DO SETOR DE LAVAGENS E MANUTENÇÕES VEICULARES}

Os resíduos gerados pelas atividades ligadas ao setor de lavagens do posto estudado são tratados e recolhidos, evitando o contato com o meio ambiente, assim, esses são coletados por uma empresa terceirizada que irá realizar o tratamento adequado, onde a mesma irá despejar os resíduos nos locais apropriados, sendo também levados para uma empresa de reciclagem. Através desta medida, o posto evita que os resíduos contaminem o solo, água e ar conforme previsto na resolução CONAMA 273/2000. Os efluentes gerados pelas lavagens de veículos são reaproveitados juntamente com os da loja de conveniência.

Na pesquisa de campo realizada constatou-se que o estabelecimento possui práticas ambientais adotadas no descarte de resíduos e efluentes gerados, como o tratamento dos efluentes líquidos oriundos da lavagem dos veículos, o recolhimento do óleo queimado, filtros usados, embalagens de lubrificantes, flanelas e estopas utilizadas nas atividades. E ainda a área de lavagem oriunda dos veículos é drenada e conectada a caixa separadora, com piso impermeável. Conforme o cumprimento dessas exigências o órgão fiscalizador do município libera a renovação da licença de operação.

Resultados semelhantes foram obtidos por Maciel e Freitas (2014) em um estudo de caso em um posto de combustível localizado na zona rural do município de Pocinhos (PB), que teve como objetivo identificar e analisar os potenciais impactos ambientais causados pelas atividades desenvolvidas, constatando que a 
empresa cumpre com as exigências da legislação quanto a destinação correta dos resíduos mais perigosos como flanelas contaminadas com resíduos tóxicos e efluentes líquidos.

No que se refere as medidas de gestão ambiental, o posto adota a reutilização da água oriunda da lavagem dos veículos para realização da limpeza do local e higienização dos equipamentos usados durantes as manutenções. Já referente as embalagens de óleos e lubrificantes, a maior parte é recolhida por uma empresa terceirizada para posteriormente realizar o tratamento, sendo que algumas embalagens dos lubrificantes são reutilizadas pelos mecânicos do estabelecimento para guardar materiais como, chaves, parafusos e porcas.

Rocha et al. (2014) afirma que os resíduos gerados pelos postos, como embalagens de óleo lubrificantes são considerados perigosos segundo normas Brasileiras e devem ter um tratamento especial em seu destino final, necessitando de manejo adequado para evitar o contato com o meio ambiente. Um estudo realizado por Muniza e Braga (2015) em uma empresa de logística na Região Norte do Brasil, evidenciou a necessidade da reciclagem dessas embalagens de lubrificantes na preservação do meio ambiente, sendo ressaltado a importância que o estabelecimento tem na conscientização dos funcionários, para que não manejem esses resíduos de forma inadequada, impactando assim, no ambiente de forma irreversível.

\section{GESTÃO AMBIENTAL DO SETOR DE CONVENIÊNCIA}

No que se refere aos resíduos gerados pela loja de conveniência (LC) do posto estudado, os mesmos são oriundos da preparação dos alimentos, restos de comida, luvas, papel provenientes das embalagens, toucas cirúrgicas, plástico, e pet são recolhidos por uma empresa privada, sendo que são manejados de forma inadequada, com risco de causarem impactos no meio ambiente, e ainda despejados diretamente em lixões da região. Segundo Lorenzett e Rossato (2010) o sucesso do gerenciamento dos resíduos somente ocorre se, os gestores desenvolverem e implementarem medidas de gestão ambiental em seus empreendimentos, para que assim, estes evitem impactos ambientais e contribuam na elevação da qualidade ambiental. Resultados semelhantes foram encontrados por Maciel e Freitas (2014) que ao realizarem um estudo em um posto de revenda de combustíveis no município de Pocinhos (PB) utilizando a análise FMEA (Análise de Falha e seus Efeitos) identificaram que o estabelecimento não realiza a separação adequado dos resíduos oriundos da LC, sendo jogados em lixões da prefeitura.

O gerenciamento ambiental adotado na LC ocorre por meio da captação e utilização da água proveniente da chuva na lavagem do piso do estabelecimento e a canalização dos efluentes gerados na LC. Segundo a FECOMBUSTÍVEIS (2011) essas medidas são importantíssimas as atividades do comércio varejista de combustível, para que assim, estes minimizem os impactos causados no meio ambiente. Além de reduzir o impacto ambiental, estas ações contribuem para a proteção da saúde humana, bem como a diminuição da poluição ambiental (LORENZETT; ROSSATO, 2010). Portanto, é imprescindível ao estabelecimento a busca por novas práticas sustentáveis e novas tecnologias para a redução de impactos ambientais, cabendo aos gestores a análise de possíveis melhorias na 
estrutura da empresa para que esta não venha a degradar o meio ambiente e causar impactos irreversíveis no meio.

Com base nas observações no posto estudado foi possível notar que a empresa possui medidas sustentáveis, como a utilização da água da chuva nas atividades e a canalização dos efluentes, porém foi evidenciado que a mesma falha na contratação de uma instituição especializada no recolhimento dos resíduos provenientes da LC. Sendo que, esta mesma iria dar a destinação adequados aos resíduos, levando-os a centros de reciclagens e aterros sanitários regularizados. Segundo Lorenzett e Rossato (2010) o uso da logística reversa em postos de combustíveis é de grande importância, pois é através dessa ferramenta que os postos proporcionaram a destinação correta dos resíduos oriundos da LC e outras atividades inerentes aos postos, evitando assim, impactos no meio ambiente. Castro (2011) observou que a logística reversa atual como um diferencial competitivo entre as empresas, assim, estas minimizariam seus impactos no ambiente gerando emprego e renda através do reaproveitamento dos resíduos sólidos.

\section{CONSIDERAÇÕES FINAIS}

O presente artigo teve como objetivo analisar a gestão ambiental em postos de revenda de combustíveis, bem como, o uso da legislação ambiental adotada por esse ramo. Para tanto, foi realizado um estudo de caso junto a um posto de revenda de combustíveis em um município do Litoral Norte da Bahia. Assim, ocorreu um levantamento dos principais impactos ambientais que o posto pode causar no meio ambiente e verificou as principais legislações ambientais que são adotadas por esse segmento.

Através da pesquisa foi possível identificar, que o posto adota medidas de gestão ambiental nos setores estudados, como a captação da água da chuva e reutilização em outras atividades, bem como a canalização do efluentes oriundos da LC. Ainda constatando que, o posto realiza o recolhimento dos efluentes e resíduos provenientes do setor de lavagens e manutenções veiculares, sendo evidenciado que o estabelecimento falha em alguns requisitos da legislação, como a manutenção periódica da caixa separadora de água e óleo.

Nesse contexto é de fundamental importância a ampliação deste estudo levando em consideração todos os postos presentes no município para verificar quais problemas a maioria apresenta no que se diz respeito a gestão ambiental. Assim é imprescindível uma maior fiscalização nesse ramo por esse ser um alto poluidor, porém é preciso uma melhor conscientização humana em relação a busca pelo desenvolvimento sustentável e uma melhor utilização de seus recursos não se preocupando apenas com o varejo de combustíveis, mas com outros ramos que impactam no meio ambiente. 


\title{
Environmental management applied to fuel supply posts
}

\begin{abstract}
The retail trade of fuel stations presents significant portion on statistics of Corporate polluters of the environment. On account of this aspect, this thread has sought to meet the two sides: the handling of petroleum products and the harmonious interaction with the environment. In this context, the need arose to analyze and identify the interaction of these entities with the environment and show what mitigating measures are taken to minimize environmental impacts. For both, this work consists of case study in a gas station in a city of the North coast of Bahia in order to verify and analyze the main environmental management measures adopted by that establishment, with reference to the existing legislation. Were used for the case study qualitative data combined with a structured interview, using the technique of observation for a better analysis of the theme. The results showed that the establishment in study performs treatment of some waste and effluents generated by activities, however lacks follow important items recommended by the legislation. However, it was found that the establishment is in the initial phase of implementation of environmental management seeking to meet fully the existing legislation.
\end{abstract}

KEYWORDS: Environmental Legislation. Environmental Management. Fuel Stations. 


\section{REFERÊNCIAS}

ABNT (Associação Brasileira de Normas Técnicas). Disponível em: $<$ https://www.brasilpostos.com.br/wp-content/uploads/2013/09/13786abnt.pdf?92a7fc > Acesso em: 3 de março 2017.

ABNT. Associação Brasileiras de Normas técnicas. NBR 14001:2015 Sistemas de gestão ambiental - Requisitos com orientações para uso. Rio de Janeiro, 2015.

ABNT. Associação Brasileiras de Normas técnicas. NBR 7505: Armazenamento em tanques estacionários. Rio de Janeiro, 2000.

ABNT. Associação Brasileiras de Normas técnicas. NBR 10004: Resíduos sólidosClassificação. Rio de Janeiro, 2004.

ABNT. Associação Brasileiras de Normas técnicas. NBR 12235: Armazenamento de resíduos sólidos perigosos. Rio de janeiro, 1992.

ABNT. Associação Brasileiras de Normas técnicas. NBR 13784: Detecção de vazamentos em postos de serviço. Rio de janeiro, 1997.

ABNT. Associação Brasileiras de Normas técnicas. NBR 15594-1: Armazenamento de líquidos inflamáveis e combustíveis - Posto revendedor de combustíveis veicular (serviços). Parte 1: Procedimento de operação. Rio de Janeiro, 2008.

ABNT. Associação Brasileiras de Normas técnicas. NBR 15594-3: Armazenamento de líquidos inflamáveis e combustíveis - Posto revendedor de combustíveis veicular (serviços). Parte 3: Procedimento de manutenção. Rio de Janeiro, 2008.

ANP (Associação Nacional do Petróleo). Disponível em: <http://www.anp.gov.br/site/extras/defesaConsumidor/fiscalizacao.asp> Acesso em: 20 de mar. 2017.

BARBOZA, D. V.; TEIXEIRA, M. A.; LIMA, G. B. A. Análise de riscos de um posto de combustíveis em Itaipuaçu utilizando a técnica HazOp. Revista Gestão Industrial, Ponta Grossa, v. 13, n. 2, p. 126-145, jun./ago. 2017.

BARATA, M. M. L.; KLIGERMAN, D. C.; MINAYO-GOMEZ, C. A gestão ambiental no setor público: uma questão de relevância social e econômica. Ciênc. Saúde Coletiva, Rio de Janeiro, v. 12, n. 1, mar. 2007. 
BRASIL. Decreto no 6514, de 22 de julho de 2008. Dispõe sobre as infrações e sanções administrativas ao meio ambiente, estabelece o processo administrativo federal para a apuração destas infrações, e dá outras providências. D.O.U. Diário Oficial da União, de 22 de julho de 2008.

BEZERRA, P. G.; CELINO, J. J.; GARCIA, K. S.; OLIVEIRA, M. R. Indicadores geoquímicos de contaminação por compostos orgânicos voláteis em águas subterrâneas da Bacia do Rio Lucaia, Salvador, Bahia. Revista Brasileira de Geociências, v. 42, supply 1, p. 238-244, dez. 2012.

CASTRO, M. D. G. Caracterização do processo de reciclagem do óleo lubrificante usado em postos de combustíveis e identificação de desafios frente à política nacional de resíduos sólidos. Dissertação de Mestrado em Engenharia da Produção, Universidade Estadual Paulista Júlio de Mesquita Filho - UNESP, Bauru, SP, 2011.

COSTA, V. M. FRANCESCH, R. F.; LORENZETT, B. D.; NEUHAUS, M.; FREITAS, L. A. R.; ROSSATO, M. V.; GODOY, P. L. Gestão ambiental em um posto de combustíveis: estudo da representatividade financeira dos gastos. Espacios, v. 34, n.3, 2013. p. 6.

CONAMA (Conselho Nacional do Meio Ambiente). Disponível em: <http://www.mma.gov.br/port/conama/res/res97/res23797.html> Acesso em: 20 de maio. 2017.

CONAMA (Conselho Nacional do Meio Ambiente). Resolução no 273. Brasília DF, 2000. Disponível em: <www.mma.gov.br/port/conama/index.cfm> Acesso em: 20 de maio. 2017.

CONAMA. Conselho Nacional do Meio Ambiente. Resolução no 237. Brasília - DF, 1997. Disponível em: <www.mma.gov.br/port/conama/index.cfm> Acesso em: 20 de maio. 2017.

FREY, M. R.; WITTMANN, M. L. Gestão ambiental e desenvolvimento regional: uma análise da indústria fumageira. EURE (Santiago), Santiago, v. 32, n. 96.2006

FECOMBUSTÍVEIS (Federação Nacional do Comércio de Combustíveis e Lubrificantes). Meio Ambiente. Rio de Janeiro: Fecombustíveis, 2011. Disponível em: <http://www.fecombustiveis.org.br/meio-ambiente.html> Acesso em: 28 mai. 2017. 
INEMA (Instituto do Meio Ambiente e Recursos Hídricos). Disponível em: <http://www.inema.ba.gov.br/atende/formularios/licenciamento/> Acesso em: 21 de mar. 2017.

IBAMA (Instituto Brasileiro do Meio Ambiente e dos Recursos Naturais). Disponível em: < http://www.ibama.gov.br/emissõeseresiduos/residuos/> Acesso em: 10 de jan. 2018.

KERBER, F. F. Atendimento a Legislação Ambiental em Postos de Abastecimento de Combustíveis: Uma Contribuição a Perícia Ambiental Criminal. 2013. $129 f$. Dissertação de Mestrado Profissional em Perícias Ambientais Criminais Universidade Federal de Santa Catarina, Santa Catarina, 2011.

LORENZETT, D. B.; ROSSATO, M. V. A gestão de resíduos em postos de abastecimento de combustíveis. Revista Gestão Industrial, v. 6, n. 2. Ponta Grossa, PR, 2010.

LORENZETT, D. B.; ROSSATO, M. V.; NEUHAUS, M. Medidas de gestão ambiental adotadas em um posto de abastecimento de combustíveis. Revista Gestão Industrial, v. 07, n. 3. Ponta Grossa, PR, 2011.

LORENZETT, D. B.; ROSSATO, M. V.; GODOY, L. P. O reconhecimento contábil dos gastos associados às medidas de gestão ambiental no segmento de abastecimento de combustíveis. Revista de Contabilidade e Organizações, v. 5, n. 11, p. 49-68. Ribeirão Preto, SP. 2011.

LEITE, P. R. Logística reversa: meio ambiente e competitividade. São Paulo: Prentice Hall, 2003.

MACIEL, D. S. C.; FREITAS, L. S. Utilização do método FMEA na identificação e análise dos impactos ambientais causados pelos postos de combustíveis: um estudo de caso. Rev. Adm., UFSM, Santa Maria, v. 7, n 4, p. 570-589, dez. 2014.

MUNIZA, I. C.; BRAGA, R. M. Q. L. O gerenciamento de óleos lubrificantes usados ou contaminados e suas embalagens: estudo de caso de uma empresa de logística na Região Norte do Brasil. Sistemas \& Gestão, n. 10, 2015, p. 442-457.

ROCHA, B. S.; SCALIZE, P. S.; ARRUDA, P. N.; CRUVINEL, K. A. S. Gestão do óleo lubrificante usado em postos de combustíveis no município de Terezópolis de Goiás - GO, Brasil. Revista Monografias Ambientais, v.13, n.4, set-dez. 2014, p.3673-3682. cross ref 
SOUSA, B. P.; LEITE, A. G.; DIAS, B. L. Postos revendedores de combustíveis e a contaminação de águas subterrâneas - prevenção de riscos e programa de automonitoramento ambiental no estado do Tocantins. Revista Científica do ITPAC. v. 4. n. 2, abr., 2011. 


\section{APÊNDICE A}

\section{Questionário}

1. Descreva a empresa: A quanto tempo funciona? Quantidade de tanques subterrâneos? Qual a capacidade de cada tanque? Qual a quantidade de funcionários? Quais os serviços/produtos que o posto presta/vende?

2. O posto de gasolina possui sistema de mangueiras e conexões que evita vazamentos durante a descarga do combustível?

3. As áreas de abastecimento são concretadas e impermeabilizadas? Os tanques subterrâneos seguem as recomendações da legislação? Essas áreas têm estão cercadas por canaletas que levam todo o efluente para uma caixa separadora de água e óleo?

4. Em alguma etapa no processo de funcionamento do posto o óleo não é lançado na rede de esgotos?

5. A empresa possui um poço de monitoramento? (Poço para periodicamente avaliar a qualidade do lençol freático a partir de análises químicas de amostras retiradas, mas também identificar uma perda de combustível

6. O que é feito com as embalagens dos óleos utilizados? (Destino das embalagens pós-consumo)

7. Qual a destinação adotada para o óleo queimado? Qual o destino das flanelas e estopas usadas?

8. É feito algum tratamento na água oriunda da lavagem de automóveis?

9. É feita a reutilização da água em alguma etapa?

10. Nas lojas de conveniência tem algum programa de destinação dos seus resíduos? (Papéis, vidros e plásticos, etc.)

11. Para o caso de ocorrência de acidentes ambientais, o posto possui pessoal treinado e equipamentos para imediato controle da situação?

Recebido: 21 jan. 2018

Aprovado: 28 ago. 2018

DOI: $10.3895 /$ gi.v14n4.7655

Como citar:

CRUZ, D. M. B.; NERIS, L. M.; MENEZES, J. D. S. Gestão ambiental aplicada a postos de abastecimento de combustíveis. R. Gest. Industr., Ponta Grossa, v. 14, n. 4, p. 1-17, out./dez. 2018. Disponível em:

<https://periodicos.utfpr.edu.br/rgi . Acesso em: XXX.

Correspondência:

Diogens Marco de Brito da Cruz

Rua Irênio da Silva Ribeiro, n 132, Centro, Alagoinhas, Bahia, Brasil.

Direito autoral: Este artigo está licenciado sob os termos da Licença Creative Commons-Atribuição 4.0

Internacional. 